by site-directed mutagenesis. The mutated NS1 was then inserted into the H1N1 virus. This recombinant virus was susceptible to the effects of IFN- $\alpha$, IFN- $\gamma$ and TNF, which indicates that Glu92 of NS1 is essential for the resistance of $\mathrm{H} 5 \mathrm{~N} 1 / 97$ to antiviral cytokines. The importance of NS1 for the pathogenicity of $\mathrm{H} 5 \mathrm{~N} 1 / 97$ was confirmed by experiments in pigs.

This study has pinpointed a lethal single-amino-acid change that renders a virus completely resistant to antiviral cytokines. But, the mechanism by which Glu92 of NS1 confers this resistance is not clear. With new strains of cytokine-resistant influenza virus lurking in Hong Kong's poultry markets, this is an important question for future research.

Jennifer Bell

(2) References and links original ReSEARch PAPER Heui Seo, $S$. Hoffmann, E. \& Webster, R. G. Lethal H5N1 influenza viruses escape host anti-viral cytokine responses. Nature Med. 8, 950-954 (2002)

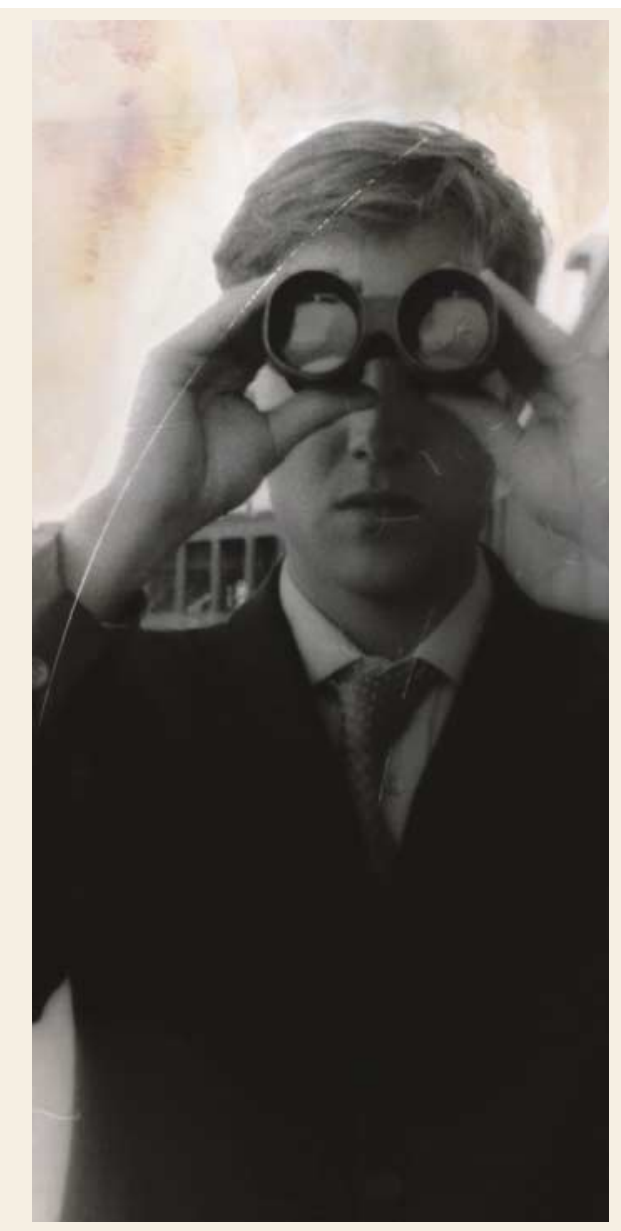

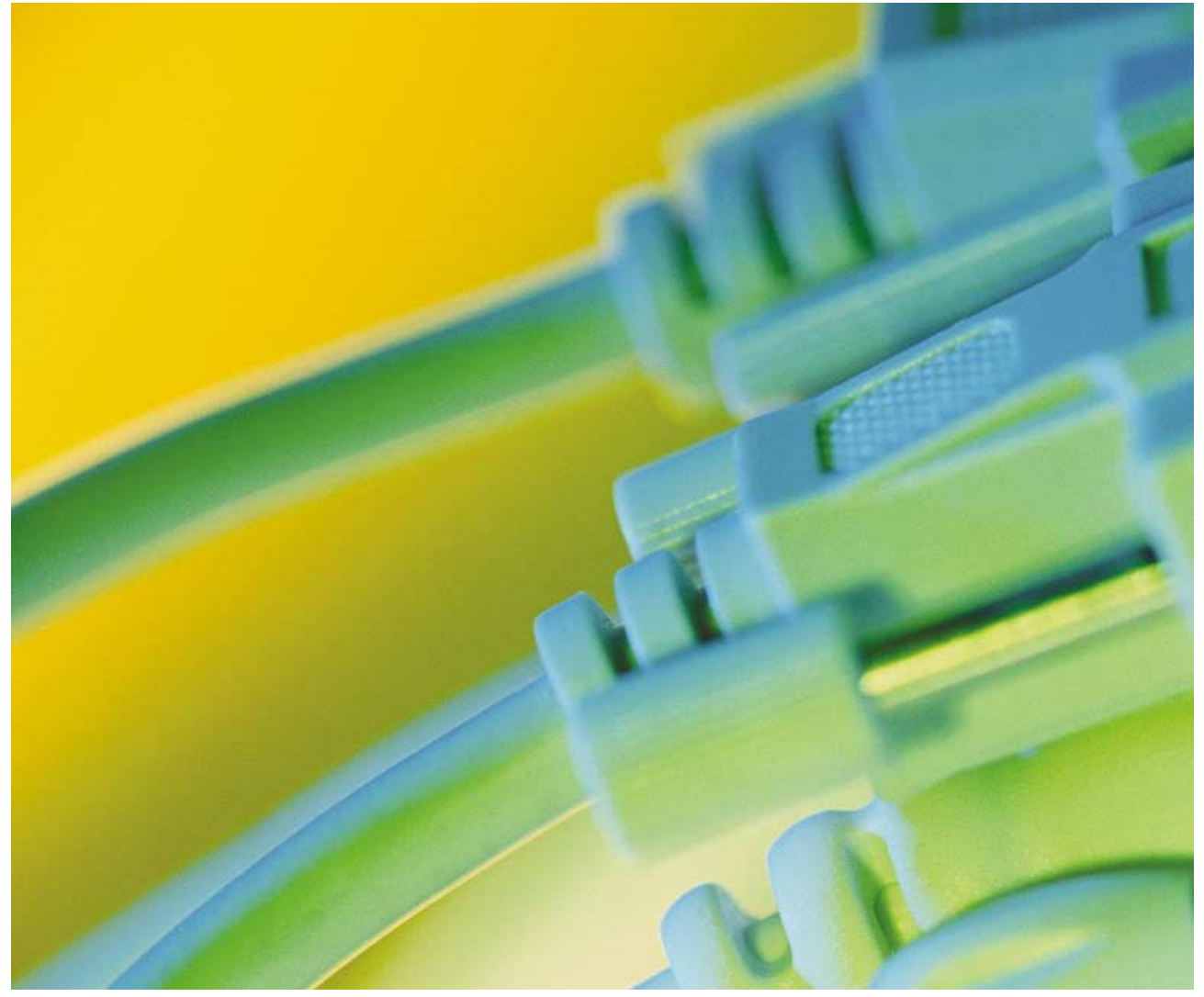

AUTOIMMUNITY

\title{
Mast cells make the connection
}

$\mathrm{K} / \mathrm{BxN}$ mice are a T-cell-receptor-transgenic model of rheumatoid arthritis in which autoantibodies specific for a ubiquitously expressed self-antigen (MHC class II) are produced. The disease can be transferred by autoantibody-containing serum. Complement, Fc receptors and cytokines - such as tumour-necrosis factor (TNF) and interleukin-1 (IL-1) — are known to be involved in disease pathogenesis in the mouse model. But, what is the cellular connection between these soluble factors and the pathogenic neutrophil infiltration of the joints that is observed in the mouse model, as well as in humans? Lee et al. think they have the answer. In a recent Science paper, they propose that mast cells are the missing link.

Mast cells are a good candidate because they are resident in the synovium and have the functional capability to produce TNF and IL-1, as well as other inflammatory mediators, matrix proteases and neutrophil chemoattractants. To analyse the potential role of mast cells, the authors used two strains of mice that lack tissue mast cells $-\mathrm{Sl} / \mathrm{Sl}^{\mathrm{d}}$ and $\mathrm{W} / \mathrm{W}^{\mathrm{v}}$ mice - owing to a deficiency of the transmembrane form of stem-cell factor (SCF) or mutations in the SCF receptor c-Kit, respectively. Both mouse strains had markedly reduced clinical and histological signs of arthritis compared with wild-type littermates after transfer of $\mathrm{K} / \mathrm{BxN}$ serum.

However, it could be that SCF-c-Kit signalling has some role in disease pathogenesis through another cellular system. To establish that the resistance to arthritis was due to the mast-cell deficiency, complementation analysis was used to assess the specific role of mast cells. Mast-cell engraftment was shown to restore arthritis susceptibility to $\mathrm{Sl} / \mathrm{Sl}^{\mathrm{d}}$ and $\mathrm{W} / \mathrm{W}^{\mathrm{v}}$ mice.

So, if mast cells are the cellular missing link, then mast-cell degranulation must be the functional link. After intraperitoneal transfer of $\mathrm{K} / \mathrm{BxN}$ serum to $\mathrm{C} 57 \mathrm{BL} / 6 \mathrm{~J}$ mice, mast-cell degranulation in the affected joints was shown to occur before any clinical evidence of inflammation, whereas no degranulation could be seen at other anatomical locations. This indicates that mast cells are involved in the initiation of inflammation. Also, degranulation continues during chronic arthritis, which indicates that mast cells might be involved in disease maintenance as well.

As for any animal model, arthritis in $\mathrm{K} / \mathrm{BxN}$ mice is not an exact replica of human rheumatoid arthritis - for example, in terms of the joints that are affected and the spectrum of antibodies that is produced, as well as the fact that the disease is more aggressive in mice. However, the similarities are sufficient to indicate that mast cells probably have a crucial role in human arthritis also. This is supported by the fact that synovial sections from humans contain a large number of mast cells, as well as immune complexes, complement fragments and SCF.

Kirsty Minton

(2) References and links

ORIGINAL RESEARCH PAPER Lee, D. M. et al. Mast cells: a cellular link between autoantibodies and inflammatory arthritis. Science 297 1689-1692 (2002)

FURTHER READING Kouskoff, V. et al. Organ-specific disease provoked by systemic autoimmunity. Cell $\mathbf{8 7}, 811-822$ (1996) 